\title{
Deepening Convictions: Religious Identity and Off-Campus Study
}

\author{
Kyle David Anderson \\ Clemson University
}

\section{Benjamin Knoll}

Centre College

\section{Ellen Tyra}

University of Edinburgh

\begin{abstract}
:
Religion is a central element in global education, fundamentally affecting how students interact with diverse peoples and cultures and what they learn and experience in foreign environments. Nevertheless, the topic has received little attention for quite some time. This study investigates how students' religious backgrounds, identities, and beliefs influence and are influenced by off-campus programs. Data collected from a number of X College students attending one of four short-term courses in January 2019 reveal the variety and depth of change in religious identities, demonstrating the need for greater awareness of this facet of student diversity and development.
\end{abstract}

\section{Introduction}

Among the many reasons people have historically traveled abroad, religious motivations are among the most prominent. Whether marking scallop shells and yellow arrows along the Camino de Santiago or prostrating on hot rock along the kora circling the Jokhang Temple, billions of travelers have carried with them across foreign terrain distinct inner hopes for personal, spiritual, and emotional enrichment.

As instructors, researchers, and administrators in global education, though somewhat reluctant to speak of religious motivations in secular society, we are constantly in the presence of learners whose religious identities and aspirations are a key part, to a lesser or greater degree, of their personal experiences abroad. While the best of intentions and social protocol compel many of us to avoid discussions of faith, educationally speaking, keeping the topic taboo leads to a substantial missed opportunity. Tackling the issue of religious education in public schools, Suzanne Rosenblith and Bea Bailey recognize the thorniness of the topic, which comes

with a whole history of reasons to reject it prima facie, but the 21 st century holds certain realities that force society to look more closely at students' religious literacy in preparing them to be participants in this democracy, as well as members of a global community. (2005, p. 94)

Encouraging greater discussion of religion is central to the development of this kind of religious literacy, a key component of students' preparation to live in a global society. In order to grasp a 
deeper understanding of new environments and peoples, the "elephant in the room" needs to be addressed, not ignored (Willis, 2012, p. 6).

At a time when institutions are demonstrating greater courage to host hard conversations about inclusion and marginalized peoples and communities, we should likewise consider expanding the vocal arena of diversity to embrace awareness of students' religion and faith. The recent Interfaith Diversity Experiences \& Attitude Longitudinal Survey observes that increases in religiously diverse friendships are tied to "meaningful encounters with worldview diversity" that challenge students to rethink stereotypes and assumptions (Rockenbach et al., 2019, p. 6). Currently, though, such discussions remain a somewhat neglected "internal" aspect of student exchange abroad (MillerPerrin \& Thompson, 2014, p. 80). In addition to broadening outlooks to improve membership in a global community (Rosenblith, 2005, p. 97), this expansion would signal greater commitment to inclusivity in study abroad (Elliott et al., 2018, p. i), while also furthering student-centered learning, and holistic development. It facilitates students' validation of themselves and, by extension, that of others.

Inspired by recent pieces featured in the Frontiers special edition on religion and study abroad (Winter 2018), this study seeks to raise awareness of how students' varying backgrounds and commitment to faith(s) affect and are affected by off-campus programming. As religion faculty know full well, not all students share the values and assumptions of a cosmopolitan world of religious pluralism. Not every learner is eager for the kind of self-examination that triggers the "discovery of multiple worlds and leads to developing an ability to hold these worlds in creative tension" (Palmer, 2015, p. 64). However, as our study demonstrates, the deepening of personal religious convictions off-campus is not always tied to the strengthening of religious absolutism or exclusivity, or vice versa. Growing our awareness of the unanticipated and divergent ways in which students' personal religious experiences and identities evolve in relation to instructors' often pluralistic and inclusive course objectives will assist us tremendously as we seek to design more engaging, comprehensive learning experiences for students off-campus. As Palmer reminds us, "if students are to be open to new paradigms, then it is imperative that we help students adequately anticipate what is in store for them" (2015, p. 69).

\section{Course Descriptions}

For this study, four courses at X College, a private liberal arts college and national leader in study abroad, were chosen for observation. These courses took place during the compact, threeweek-long January 2019 winter term (or X Term), in which students take a single intensive course. The particular courses in question for this study, "The Art of Pilgrimage," "The Roots of Mindfulness," "Islam in America," and "Imagining Home: Global Migrations and Religious Identities," were selected because they were led by instructors from X College (those most familiar with their students), contained prominent religious components, and occurred in unfamiliar, offcampus environments. While not all these courses were offered under the "Religion" curricular designation, each included components intentionally crafted to have students directly encounter and examine religious cultural difference in some way. Our decision to include the "Islam in America"

and "Imagining Home" courses in this study aligns with current shifts in the conception of global learning as education that takes place in national as well as international spaces. 
The first course, "The Art of Pilgrimage," took place in Spain, along the famous Camino de Santiago pilgrimage trail. This intensive experience offered students the opportunity to walk portions of the well-trod route through northern Spain, following over 1,000 years of footsteps of devoted pilgrims. It was a substantial foray into experiential learning, where students were encouraged to contemplate both the physical, ritualized act of pilgrimage as it has existed throughout history and the effects that that pilgrimage had on their understanding of faith. Throughout the course, stops were made in towns along the trail to examine religious art and architecture that have been developing since the medieval period.

"The Roots of Mindfulness" course was cross-listed as a Psychology and Environmental Studies class but included site visits and curriculum that had distinct religious themes. Students were required to read about Zen Buddhism and Shinto, two religions with considerable populations of adherents in Japan, prior to their departure from the United States. In Kyoto, where the course primarily took place, students were exposed to various religious sites, such as temples, shrines, and other sacred spaces in Japanese culture. The course instructors encouraged students to engage with the spaces and approach them with reverence, though not in any particular religious mode. However, how students chose to interpret and partake in the space was left open to them. Whether students were seeking a religious experience or not (either in their own tradition or another), they were prompted to approach sites as if such an experience were possible. Themes combining psychology and the environment, such as mindfulness as a mental health tool and the innovative practice of forest therapy, were discussed in terms of Japanese religions and spirituality.

"Islam in America" focused on the cultures, history, and transformations of Muslim communities in the United States. A key element of the course was that students were encouraged to contemplate the diversity of faiths that exist in the United States, as well as within the tradition of Islam, and to draw their own nuanced conclusions based on key site visits and personal reflection. Students began their studies on X College's campus where the major themes of the course were outlined and a basic framework of understanding of Islam was established. Next, a ten-day trip to Washington, DC, New York City, Dearborn, MI, and Raleigh/Chapel Hill, NC, allowed students to interact with leaders in various Muslim communities. To conclude the course, students returned to $\mathrm{X}$ College's campus to discuss and reflect upon what was seen, heard, and experienced during offcampus instruction.

Finally, the course "Imagining Home: Global Migrations and Religious Identities" was offered only to first-year students. This course focused on questions of defining "home," especially with regard to diaspora communities and their experiences, both past and present. The specific goal of the course was to open students' eyes to the differences that exist in their own "backyard," changing their own presumptions about what "home" and "abroad" are in the process. The course instructor intended the experience and associated coursework to challenge accepted notions of truth and allow students to reflect on what a multiplicity of perspectives might look like. Journaling was a highlight of the course that offered students a creative and open format to process their own reactions and ideas. Similar to "Islam in America," "Imagining Home" included a domestic off-campus, experiential learning component consisting of a four-day trip, bookended by on-campus classroom instruction. Minneapolis and St. Paul, Minnesota were the primary locations of course activity, and 
where the class focused heavily on religious spaces and communities with origins in Africa, Asia, and the Holy Lands.

In an increasingly globalized and interconnected world, students will need to be prepared to interact with individuals of various backgrounds and religious identities (Braskamp et al., 2009). The programs chosen for this study occurred during the same time period and all brought students into direct contact with religious practices, practitioners, and spaces, thereby inviting them to cultivate a deeper understanding of those traditions. This direct contact with the real world was intended to create strong resonances as a "lever of change" for students (Gardner, 2006; Poag \& Sperandio, 2015).

\section{Research Foundations}

Religion is often dealt with in global education as one more central but nebulous feature of local culture-part of the general package of engaging with local communities and being respectful of local customs (Elliott \& Romito, 2018).

In an off-campus course that does not deal explicitly with religion, it is unlikely that students will have specific opportunities to explore religion in descriptive or personal ways. This can be somewhat confusing when students find themselves in these new landscapes. As Owen Willis explains, participation in an off-campus program in a community where religion is ever-present and yet not addressed can be fairly disorienting (2012). The complex reality of host communities may not be fully understood without delving into religious topics. Thus, when religion is bypassed, so too is the potential for crucial development in intercultural skills and interfaith dialogue (Unkule, 2018).

The accepted benefit of off-campus study is that it complicates knowledge for students most often communicated through texts and lectures. Outside the walls of the classroom, they experience the variety of performance and life that escape tidy punctuation on a page. Moreover, immersion in a foreign context has the power to destabilize their sense of being the universal or standard measure - the omnipotent, unmoved observer. Palmer sees this potential as being study abroad's most valuable aspect:

The worldview of the student becomes a primary object of study; examined, as it were, by the particulars of the religious and other cultural norms nominally under investigation. Unless a student withdraws completely into herself or flatly rejects the viability of another religious or cultural perspective, her own worldview will necessarily be interrogated in light of the new norm in which she is immersed. (2015, p. 67)

More than just gaining new insights into another religion or culture, then, students' own sense of personal and cultural gravity becomes relativized: their home religion and religious views become so many points on a broader spectrum of world faiths.

The embodied nature of their experiences contributes to this "healthy, constructive disequilibrium" (Miller-Perrin \& Thompson, 2014, p. 86) as the novel climates, sounds, scents, and architecture enveloping them become part of a new fabric for personal meaning-making. Reflecting on his courses abroad with students, Elijah Stiegler writes: 
Students abroad will understand what a "sense of place" is easily. The twelve students I brought to Ladakh in 2009 learned more about a fifteenth century Gelugpa monastery from climbing up a huge set of steps before arriving at gigantic wooden double doors, than from reading about Ladakhi Buddhist history. (2015, p. 41)

Being more aware of their bodies in physical places enriches learning. As Richard Carp explains, "material and bodily investigations of religion constantly remind students and teachers how our own bodies and sensory training are implicated in our ability to know and understand" (2007, p. 11). This locative, experiential knowledge and contingent self-awareness can disabuse students who expect "cultural immersion" without getting their hands dirty. At the same time, experiencing this sort of relativization of their cultures and beliefs can be quite disconcerting.

Students face a myriad of challenges while studying off-campus, including homesickness, linguistic and cultural barriers, financial stress, "fear of missing out," the pressures of increased responsibility and independence, course work, etc. (Li et al., 2013). The influence of these factors varies in manifestation and intensity depending on the student. They often are exposed to situations that can challenge their most fundamental thoughts and beliefs, something that touches their very identity. Research suggests that when this occurs, students may be inclined to turn to their religious identity to restore stability and comfort (Miller-Perrin \& Thompson, 2010).

Neglecting the topic of religion in study off-campus may exacerbate students' feelings of grief or loss as they confront profound change and challenges. Gray and Savicki's (2015) study of the complexities of re-entry for students point to feelings of loss that include "readapting to the pace of life at home," "accepting your study abroad experience has ended," "finding a level of intensity at home that you experienced abroad," "leaving the pace of life in the study abroad country," "leaving host country friends," etc. (p. 218). Grief was found to be highest for students with little preparation for re-entry coupled with difficulties linked to loss. On the other hand, those who prepared themselves for loss did better adjusting to their return. As a result, Gray and Savicki advocate that instructors prepare students for loss experiences and notice symptoms accompanying such loss: "A sensitive faculty or advisor receiving a reentering student would do well to peruse the intensity factors of each specific student to develop a more holistic picture of potential issues that each student might face" (p. 217). Though not considered an influential factor in their study, perceived and explicit challenges to one's religious identity are profoundly destabilizing for learners. Thandiwe Dinani's (2018) and Miller-Perrin and Thompson's (2010) studies on faith and study abroad indicate how students turn to their home religion for comfort and guidance when confronting the stress of foreign environments:

Students who study overseas, for example, may be more inclined to encounter day-to-day circumstances that push them to rely on their faith in order to deal with the challenges of living in another culture. Faith may serve as one of their first coping mechanisms in situations where they encounter doubts, confusion, and the unknown of living abroad. (Miller-Perrin \& Thompson, p. 96)

This is, of course, an ambivalent return to personal faith, as it is often provoked by stress and pressure from without. Off-campus programs most often place students in novel contexts where their religious values are seen as foreign and marginal, distancing them from traditional sources of religious authority. Any challenges to that set of beliefs are typically taken very personally, and any 
substantial change in faith may subsequently develop into a sense of deep personal loss. Being aware of the kinds of personal religious challenges students might undergo will aid instructors in guiding their learners to understand, integrate, and recover better from such experiences upon re-entry.

Results of our study below at X College are offered as a prelude to the range of potential movements in personal faith that students might experience off-campus, in line or at variance with explicit academic course objectives. They provide an interesting point of comparison to MillerPerrin and Thompson's influential 2010 study, where students were found to have increased their daily religious practice and made significant gains in identity achievement as a result of studying abroad.

Furthermore, our study builds upon Poag and Sperandio's 2015 work by parsing out the specific manners in which change in faith does or does not occur. While Poag and Sperandio report substantial changes in student faith, our study offers some explanation for a lack of reported change with reference to internal and external factors.

\section{Methodology}

We examined the potential impact of study abroad experiences on student pedagogical and religious/faith-related outcomes using a survey of undergraduate students who participated in one of the three-week, January 2019 term courses (X Term courses) that had a substantive religion/faith component (see above). All students who participated in one of these four courses were invited to participate in an IRB-approved online questionnaire fielded in May 2019 and were incentivized to participate with the option to be entered into a random drawing for a $\$ 10$ cash gift card upon completion. Out of a total of 69, 39 students completed the survey, a response rate of approximately 57\%. The median completion time was approximately 20 minutes (the majority of students answered every question).

To assess the effect of the study abroad/away course on the outcomes of interest, we invited students to complete a series of pre- vs. post- recollections about their views. First, we asked a series of questions that prompted students to: "Think back to December 2018 BEFORE you took the X Term course. How would you have answered the following questions? Try to remember as best you can and be as candid and honest as possible." After completing that portion of the survey, they were then prompted: "We will now ask you a similar set of questions. This time, answer them according to your CURRENT thoughts and opinions as they are today and right now." Ideally, the same survey instrument would have been administered before the course and then repeated afterwards, but given that six months had elapsed between the study abroad/away experience and the time they were invited to take the survey, we did not find it unreasonable to expect that students would be able to do an adequate job of recalling their general thoughts and impressions before the experience as compared to after. That said, it is of course possible (if not likely) that their recollections of their pre-course impressions were influenced by their experiences on the trip.

As will be seen in some detail below, we included in the survey measures of student religiosity and spirituality using questions drawn from the General Social Survey (gss.norc.org) and the 2014 Pew Religious Landscape Survey (RLS) (https://www.pewforum.org/religious-landscape-study/). We also included in the survey measures of student attitudes toward societal religious diversity 
(dis/agreement that "our nation's increasing religious diversity [is] an overall positive trend for the future"; see the Pew RLS), favorability toward various religious outgroups using a "feeling thermometer" scale (see Nelson, 2008), perceived social distance between the student and various religious groups using a "Social Distance Scale" that measures whether the respondent would be willing to accept a member of a particular group as a visitor to one's country, citizen of one's country, coworker, neighbor, close personal friend, close relative by marriage, or marriage partner (see Geisinger, 2010), and political and social tolerance toward various religious groups using a "least-liked" group tolerance measure where students are asked how willing they would be to extend civil liberties to the religious group they had the lowest degree of favorability toward on the "feeling thermometer" scale (see Sullivan, Piereson, \& Marcus, 1979). For each of these questions, we used a randomized battery of religious groups that included: "Roman Catholics, Evangelical 'born again' Protestants (e.g., Baptists, Pentecostals), Mainline Protestants (e.g., Methodists, Presbyterians, Episcopalians), Latter-day Saints (Mormons), Eastern Orthodox Christians, Jehovah's Witnesses, Jews, Muslims, Buddhists, Hindus, Atheists/Agnostics, Shintos, Baha'is, Native American religionists, Sikhs." (Please see citations in this paragraph for lengthy treatments on the development, validity, and reliability of these survey questions; the full survey instrument is available in Online Appendix 1.)

In terms of respondent characteristics, 17 students took part in the "Art of the Pilgrimage" course, eight in the "Imagining Home" course, seven in the "Roots of Mindfulness" course, and six in the "Islam in America" course. Of the 38 students who answered the question, eight were firstyears, eight were sophomores, 11 were juniors, and 11 were seniors. Roughly four of five participants were female, 27 identified as "white" race/ethnicity, five as "black or AfricanAmerican," four as "Asian," and two as "other or mixed race" (both gender and race/ethnicity responses were representative of the total population of 69 students who enrolled in one of the four courses). There was diversity in the religious background of our students as well, with about a quarter reporting that they attend religious services either weekly or never and half attending either occasionally or semi-regularly. About one in four reported that religion is very important in their lives while a third said that it is somewhat important; the remaining said that it is not too important or not at all important.

Students were also asked to indicate (open-ended response) their "present religion, if any." To aid in analysis, we then grouped student religious self-identities by the following categorization schema: Evangelical Protestant (most Baptist, nondenominational Christian, and Pentecostal denominations), Mainline Protestant (most Methodist, Presbyterian, Episcopal, Disciples, and United Church of Christ), Roman Catholic, Unaffiliated ("nothing in particular," atheist, agnostic), and Other non-Christian. This schema groups religious communities within broader American historical traditions and is the same used by Pew Research Center and recommended by scholars Smidt et al. (2009, Chapter 1) and Putnam and Campbell (2010, Chapter 1). Within this schema and among the 38 students who answered the question, 12 identified as an Evangelical or nondenominational Christian, three as a Mainline Protestant of some kind, eight as Catholic, 12 as atheist/agnostic, and three as non-Christian. Finally, about two-thirds of students reported having the same religious identity that they were raised with, the most common alternative being those who were raised in a specific tradition and now identified as agnostic/atheist. 
To dig deeper for other potential effects of the study abroad/away courses on personal religious experiences, attitudes, or spirituality, the survey ended by asking students to answer two open-ended essay questions:

In a few sentences or paragraphs, please describe how your religious background, identity, and/or belief (or lack thereof) influenced your X Term 2019 experience?

In a few sentences or paragraphs, please describe how your X Term 2019 experience influenced your religious identity and belief (or lack thereof)?

Students were free to enter as much text as they liked, and most students provided a few sentences for each essay prompt, usually around 50 words.

One of us $(\mathrm{X})$ was responsible for the analysis of the open-ended qualitative responses to these questions and employed structural, "in vivo," and pattern coding techniques throughout to assess the various themes and patterns that emerged from the responses. This involved two phases of analysis and interpretation. During the first phase, $\mathrm{X}$ read through the responses a few times using both the structural and "in vivo" analytical coding approaches. The structural coding technique involves focusing on specific topics or themes and coding them accordingly, a methodology routinely used for analyzing interview-based qualitative data. The in vivo approach looks for explicit words and phrases used by the respondents that emphasize ideas or concepts that suggest how the respondent might be thinking about the issues. This approach prioritizes the voice and associated interpretation of the questions on the part of the respondent. After this first review of the openended responses, $\mathrm{X}$ then switched to a "pattern coding" approach, which is designed for use during the second phase of the qualitative analysis and interpretation. This approach takes the various codes discerned from the first phase of the analysis and attempts to group them into a smaller number of "meta-coding" umbrella codes that reveal consistent and dominant patterns in the responses. (For more information on each of these approaches, as well as the philosophy of multiple-cycles coding and interpretation of qualitative data, see Saldaña, 2012). Ultimately, this multiple-cycle interpreting coding process yielded four key subthemes: 1) religious orthodoxy, 2) favorability toward those of other faiths, 3) personal belief, and 4) spiritual experiences while off campus.

Of course, the analysis and interpretation of qualitative data is always to some extent a subjective exercise, influenced by the interpreter's background and life experiences. In this case, X's professional background is that of a literary scholar and an expert on global learning with a long history of living, teaching, and working in the Americas, Europe, and Asia; X currently serves in an administrative role in global education at a large public university. While $\mathrm{X}$ grew up in the northeastern United States (Rhode Island and Vermont), X spent extended periods of time as a child in the United Arab Emirates and the United Kingdom, and also participated in a two-year period of missionary service in Italy as a teenager. As a member of a minority religious faith, Mormonism, $\mathrm{X}$ is sensitive and sympathetic to the challenges of other marginalized groups and religious communities across the globe. Due to personal transformative experiences abroad over the years, $\mathrm{X}$ welcomes change and is keen to recognize and support it in students. The strongest motivation to conduct this study grew out of numerous recent conversations $\mathrm{X}$ has had with members of communities in the southeastern United States who often make reference to their first 
international experiences as having had religious purpose. $\mathrm{X}$ has published on this topic in popular outlets, calling for educators to engage more directly with religion in order to understand students' positionality, to anticipate their needs and challenges while studying abroad, and to foster a more holistic approach to education. In spring 2019, X launched two inaugural talks at X College for faculty, staff, and students on religion and diversity in study abroad.

Finally, due to the preliminary and exploratory nature of our study, we report here the "raw numbers" of the quantitative survey results, without post-hoc stratification weighting or other remedies for dealing with unrepresentativeness. Due to the small number of respondents, we make no claims of statistical significance or generalizability to either the wider student body of X College or U.S. undergraduate students at large. Instead, we interpret our exploratory results as general patterns from the three dozen or so students who participated in study abroad/away courses in January 2019 at X College that involved a strong substantive focus on faith, spirituality, and/or religion. We report these preliminary findings with hopes that they will spark further research and more large-scale analysis going forward.

\section{Results}

\section{Views on Religious Diversity}

One of the key pedagogical goals for these January courses was to expose students to religious diversity in the United States and the world, and to grapple with its implications for U.S. and global society. To assess this outcome, students were asked to report (pre- vs. post-) their level of agreement with the following statement: "I see our nation's increasing religious diversity as an overall positive trend for the future." As shown in Figure 1, roughly one-quarter of students reported higher levels of agreement after the course compared to before. Of course, students were largely in agreement with this statement to begin with, as only four of 38 reported that they "somewhat disagreed" that increasing religious diversity was a societal good compared to 15 and 19 who "somewhat" and "strongly" agreed, respectively. Comparing pre- vs. post-, 27 students did not change their answer, while eight of the remaining nine reported higher levels of agreement. They tended to be the students who enrolled in the "Art of the Pilgrimage" and "Imagining Home" courses, as well as more likely to be of the same religious identity with which they were raised.

To the question how "religious background, identity, and/or belief (or lack thereof)" influenced their experiences in the course, students often demonstrated their prior openness to religious diversity (italics added):

I am multicultural, so I was excited to learn about even more cultures. Because of my background, I noticed similarities in almost every faith tradition to at least one of my own so it was very nice to see how despite our differences, we essentially belief in the same things. (student 35)

My background of taking a world religion class in high school allowed me to have a very basic understanding of some of the traditions. My personal belief was to keep an open mind to every tradition. (student 32)

I wasn't that influenced [by] my own religion because I was open to learning more about religions other than my own and was accepting of the teachings. (student 29) 
My upbringing at home more than anything impacted me. I've always been taught that all religions are important and I think that led me to experience everything to the fullest and have an open mind about all traditions. (student 15)

Six respondents explicitly mentioned how their religious background made it more challenging for them to be open to other traditions, having had "very little experience learning about other religious practices," a background that made them "more skeptical towards religions," or made them take a "fairly narrow approach" to their experiences.

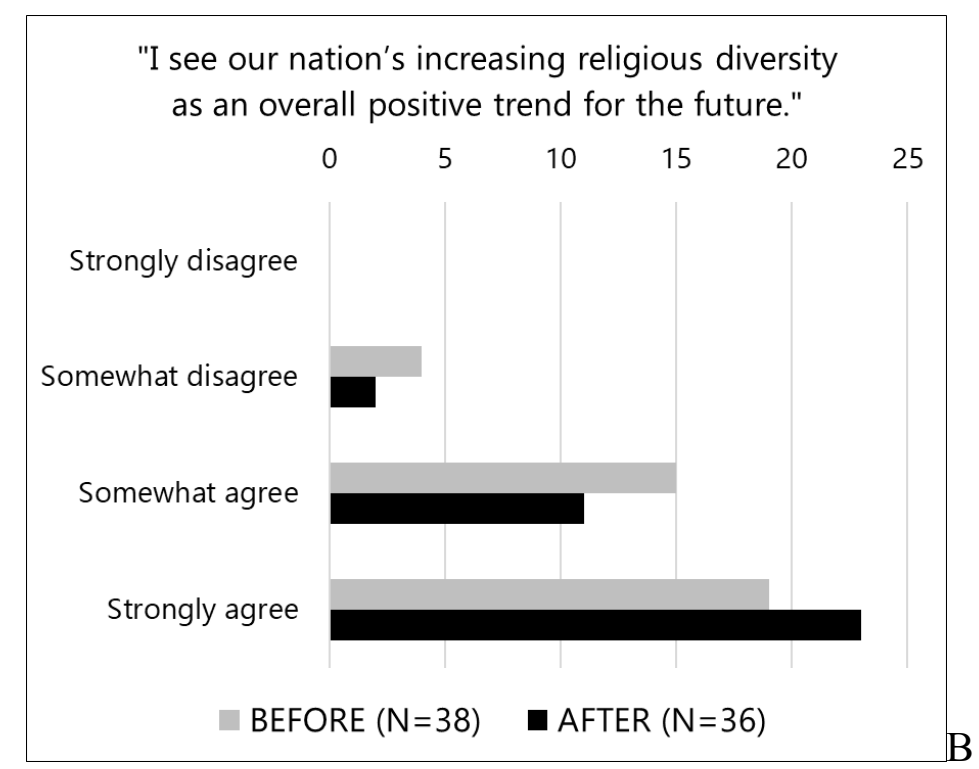

Figure 1. Agreement that increasing religious diversity is a social positive, pre- vs. post-.

\section{Favorability Toward Religious Out-Groups}

Three of the four January courses focused on religious minority groups in the United States and abroad. We asked students to rate their favorability toward a series of religious groups using a "feeling thermometer" scale (Nelson, 2008), with 0 being very cold, 50 being lukewarm/ambivalent, and 100 being very warm, then compared pre- vs. post- responses. Figure 2 shows the average degree of change on the feeling thermometer scale toward each group, with pre-course favorability levels indicated in parentheses in the figure (rounded to the nearest unit).

As can be seen in Figure 2, students became, on average, a little warmer toward Muslims, Baha'is, and Sikhs ( $6 \%$ average increase in favorability) as well as toward Shintos, Hindus, and Mormons (4\% increase). There is evidence of minor favorability increases toward Buddhists, Jehovah's Witnesses, and Evangelicals (3\% increase) as well as toward Jews and Native American spiritualists $(2 \%$ increase).

We note a curious effect that views tended to become less favorable toward atheists/agnostics by about $5 \%$ on average. We find this a notable and intriguing pattern in that an intensive study abroad/away experience with a strong focus on faith, spirituality, and religion tended to produce 
more antagonistic feelings toward those whom students may perceive to be irreligious and hostile toward religion, based on popular stereotypes (Wright \& Nichols, 2014). One of the respondents shared why this might have been the case for them:

It strengthened my religious identity because it made me think how can God not be real. He has given us the ability to build such beautiful communities of love and trust. That is why my favorability towards atheists went down. It would baffle me that one could make this pilgrimage [. . .] and reject that the divine inspired people to participate and create. (italics added) (student 21)

Ultimately, though, the pattern seems to be that these study abroad/away courses improved attitudes toward members of minority religious groups to some extent. The effect tended to be strongest among students who took the "Islam in America" and "Imagining Home" courses, both of which were primarily focused on minority religious communities in U.S. society. Though many of these "out-groups" were never mentioned by name in students' qualitative responses (e.g., Baha'is, Sikhs, Hindus, Mormons, Jehovah's Witnesses), it is easy to imagine that responses such as the following explain this increase in favorability:

My X Term 2019 experience has taught me that there are a lot of different religions and spiritual people in the world. A lot of the sites we visited and the different people we met were new knowledge to me. They also debunked a lot of misconceptions that I had about them. I now feel like I want to explore more religions because the people were so inspiring. Their religious and complex identities were really compelling. (italics added) (student 13)

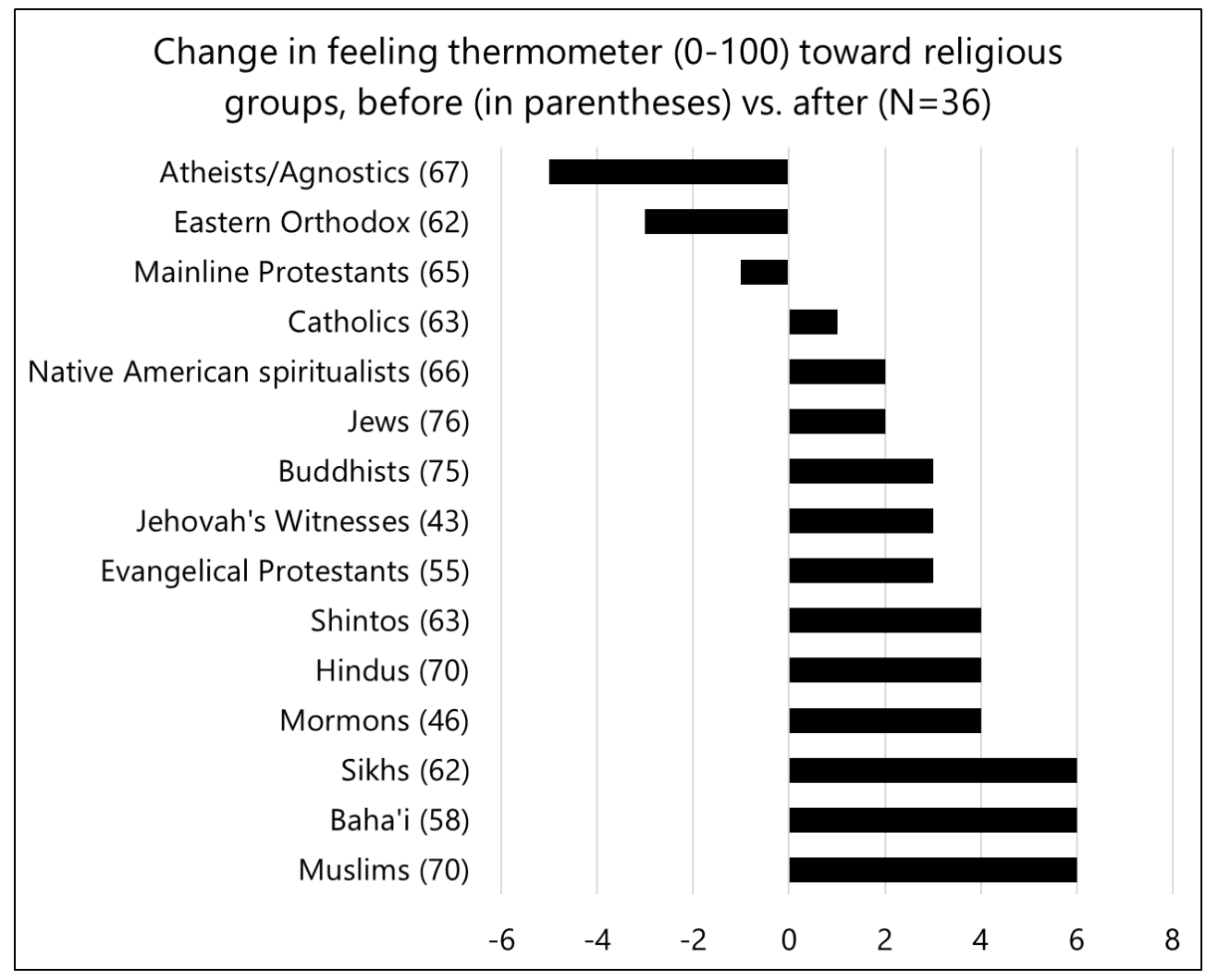

Figure 2. Favorability toward religious groups in America, comparing pre- vs. post-. 


\section{Perceptions of Social Distance}

Given that several of the courses focused on attitudes toward religious outgroups, we also asked questions probing students' perceived social distance from the same list of groups as analyzed with the feeling thermometer question. One may have favorable opinions toward a group but still be wary of inviting individual group members into one's close circle of friends or having them as a neighbor or coworker. The "Social Distance Scale" (Geisinger, 2010) assesses a person's perceived social distance from a particular group by asking a series of questions about whether the respondent would be willing to accept a member of a particular group as a visitor to one's country, citizen of one's country, coworker, neighbor, close personal friend, close relative by marriage, or marriage partner. Alternatively, respondents can also indicate that they would "exclude" members of that group from their country.

As before, we asked students to indicate the closest degree of relationship they would be willing to accept with each religious outgroup, comparing pre- and post- measures toward each group. On a 1-7 scale (with each unit corresponding to an increasingly narrow degree of perceived social distance), we observed no substantive change in perceived social distance between the various groups in question (those listed in Figure 2). The average change toward all groups was 0.02 in a more favorable direction, with no group reporting an average change of more than 0.15 units on a 1-7 scale. We also found no substantive patterns between students depending on their personal demographic characteristics, religious backgrounds, or which course they took in January 2019.

While we might be tempted to conclude that exposure to religious outgroups in a study abroad/away setting has no effect on one's perceived social distance toward these groups, it should be noted that social distance scores were extremely high in the pre- responses, an average of 1.8 on the 1-7 scale, somewhere between being willing to accept as a marriage partner and a close personal friend. (Only Shintos, Baha'is, and Native American spiritualists were placed, in terms of our students' willingness to accept them, between a close personal friend and a neighbor.) Thus, perhaps the study abroad/away experiences had little effect on social distance scores precisely because there was so little room for improvement to begin with: students by and large were already quite willing to accept members of religious outgroups as marriage partners or close personal friends before the course and those opinions remained largely unchanged afterwards.

\section{Political/Social Tolerance}

We also investigated whether political tolerance toward religious outgroups was affected by the study abroad/away experiences. Political science research has for several decades used a standard survey approach to measure political tolerance in the United States (see Sullivan, Piereson, \& Marcus, 1979). First, respondents are asked to indicate their levels of favorability toward a list of social groups (e.g., socialists, Republicans, blacks, Ku Klux Klan members, atheists). Then, they are asked how willing they would be to extend civil liberties to whichever group they indicated being least favorable toward (the "least-liked group"). In our case, students were asked their level of support for their least-liked religious outgroup (i.e., whichever they indicated as lowest on the feeling thermometer question) being "permitted to make a public speech in my city," "being permitted to run for political office in my city," and "having a place of worship in my city." To gauge more basic social tolerance, they were also asked whether they would "support a close friend or family member 
converting to [their least-liked group's] religion" or whether they would "enthusiastically vote for a member of this group if my party nominated him or her for the presidency."

As with the social distance scale, we did not observe any substantive changes in students' attitudes when comparing pre- to post- answers to these questions, even among various demographic or religious subgroups. Approximately two of every three students said that they "strongly agree" with extending civil liberties to their least-liked group, and three-quarters with permitting them to have a place of worship in their city. Once again, the lack of effect may be due to the pre-existent willingness of students to extend civil liberties to least-liked groups before the class, when only three students (of 38) indicated that they would somewhat or strongly disagree with a member of their least-liked group being permitted to run for political office and no student objecting to a group member making a public speech in their city or having a place of worship in their city.

By contrast, when asked for their recollections of attitudes before the study abroad/away experience, about half of the students said they "strongly agree" that they would support a close friend or family member converting to their least-liked religious group's faith or that they would enthusiastically vote for a member of this group for president. About a third (13 students) said that they somewhat or strongly disagreed that they would support a close friend or family member converting to their least-liked group's religion and about one in five (eight students) said that they would likely not vote for a member of their least-liked group for president. If anything, students became slightly more hesitant to support a close friend or family member converting to their leastliked group's faith, with four students reporting being less likely compared to two students being more likely (with the other 30 remaining unchanged in their views).

\section{Belief in God}

We attempted to assess the effect of these study abroad/away courses on personal religiosity and spirituality in a variety of ways. The first was simply asking about students' belief in God using the standard question from the General Social Survey. Thinking back to before their January experience, seven students reported that they believed in God with no doubts, 12 that they believed in God, albeit with some doubts, seven that they believed sometimes but not at others, seven in a "higher power" of some kind, and five an agnostic "I don't know" and "I don't believe there is any way to find out." No student selected the unambiguous "I don't believe in God" response.

Figure 3 compares these responses with post-experience assessments, where 29 students reported that they did not change in their belief about God, but seven (about one of every five) students did. Of those, six students reported moving one degree in a more believing direction while one student reported moving two degrees. It is interesting to note that of those who moved in a more believing direction, all except one was enrolled in the "Pilgrimage" class, which was specifically focused on the history of spiritual pilgrimages and included frequent visits to churches and other sacred sites in Spain. There is likely some self-selection effect here, with students enrolling in the class likely open to a spiritual experience of some kind, and indeed, six of the 17 students (roughly one in three) reported that they were strengthened in their faith in God when comparing pre- to post- measures. 
Qualitative responses demonstrating how previously held faiths were strengthened include (italics added):

This trip definitely affirmed my own faith even further, but also exposed me to other religions that I never really had learned. For my own beliefs, I think this was important because it further validated what I already believed, but allowed me to question my own faith and really think about why I believe. The whole story of St. James that was carried throughout this trip was something specific that influenced my experience because it put a purpose with what I was doing. (student 28)

My faith grew a little during my trip, but not as much as I thought it would. I did become more aware of what it means to be religious and that I should practice my faith more. (student 7)

I have always been skeptic[al] about my religion. I've always seen it as a tool of oppression. However, taking this class helped me change my perspective and realize how important role it plays in shaping my identity. (student 12)

After the Camino, I feel a deeper appreciation for my religion. With so many people of so many different faiths walking it, it made the trip all the more special knowing, as a Catholic, this connected me to so many previous pilgrims; it also proved how encompassing religion can be when all involved seek the common goal of acceptance and belief. (student 31)

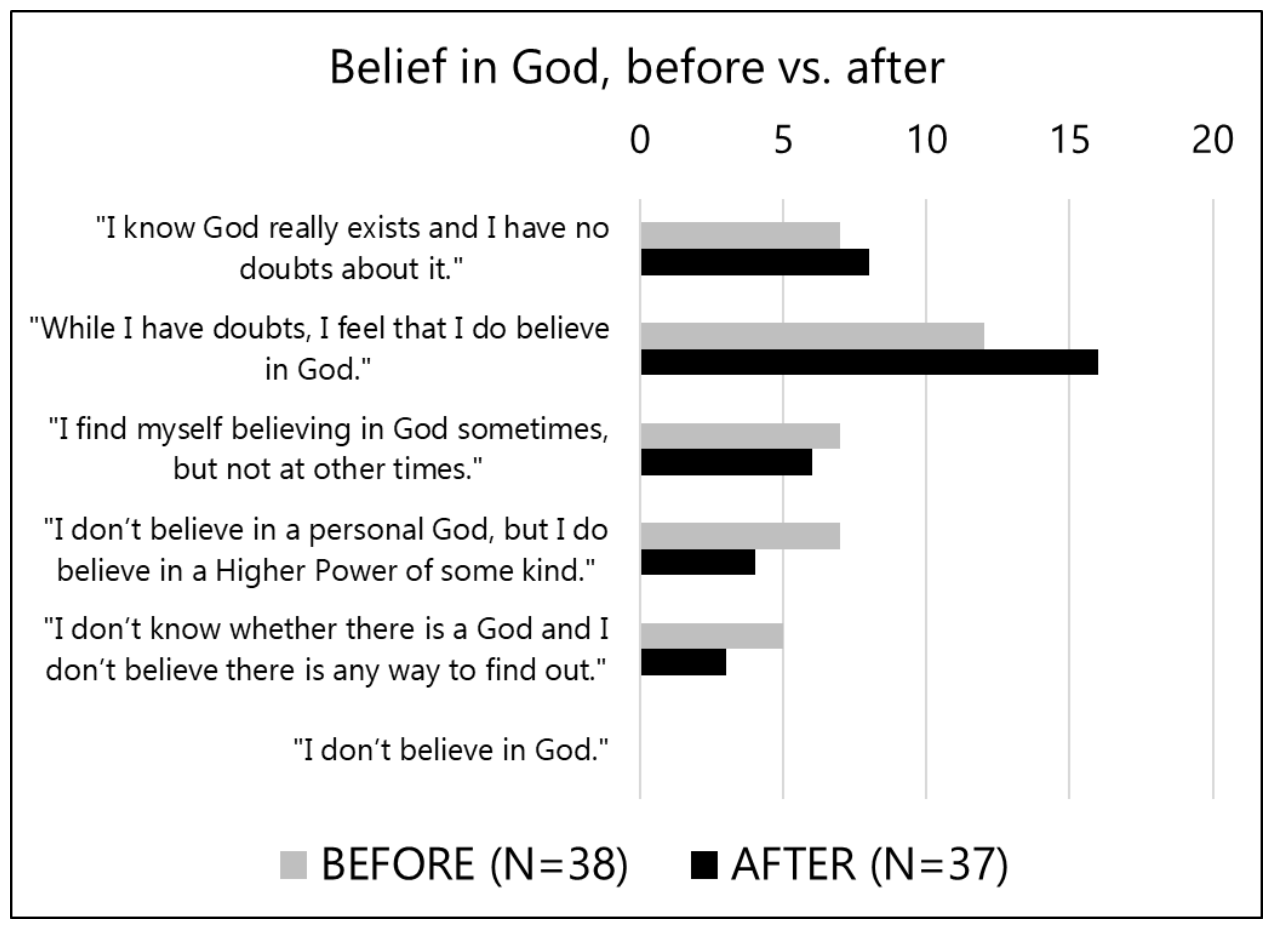

Figure 3. Self-reported belief in God, comparing pre- vs. post-.

\section{Spiritual Experiences}

The instructor's goals for one of the courses ("Roots of Mindfulness") explicitly included exposing students to locations where they might experience a sense of "sacredness." In their pre- 
experience recollections, nine students reported that they had experienced "transcendent, spiritual, or sacred" moments in their lives within their own religious tradition and another ten students reported having had these experiences both within and without their own religious tradition. Roughly half (19) the students reported that they had never had such an experience.

Figure 4 compares these responses with their post-experience recollections. Those that reported having had spiritual experiences either exclusively within or both within and without their own religious traditions increased from 19 to 24. Those who said that they had "never" had such an experience decreased from 19 to 12. Notably, about one-third of students who in the pre-experience assessment reported "never" having spiritual experiences recalled that after the study abroad/away experience, they now had experienced one. We also found that these students were those who had enrolled in the "Pilgrimage" or "Imagining Home" courses.

One of the student respondents shared how they

had several religious experiences, such as mass and watching the sunset, as well as some reflective time, which allowed me to refocus and redefine my own relationship with religion and with God. (student 22)

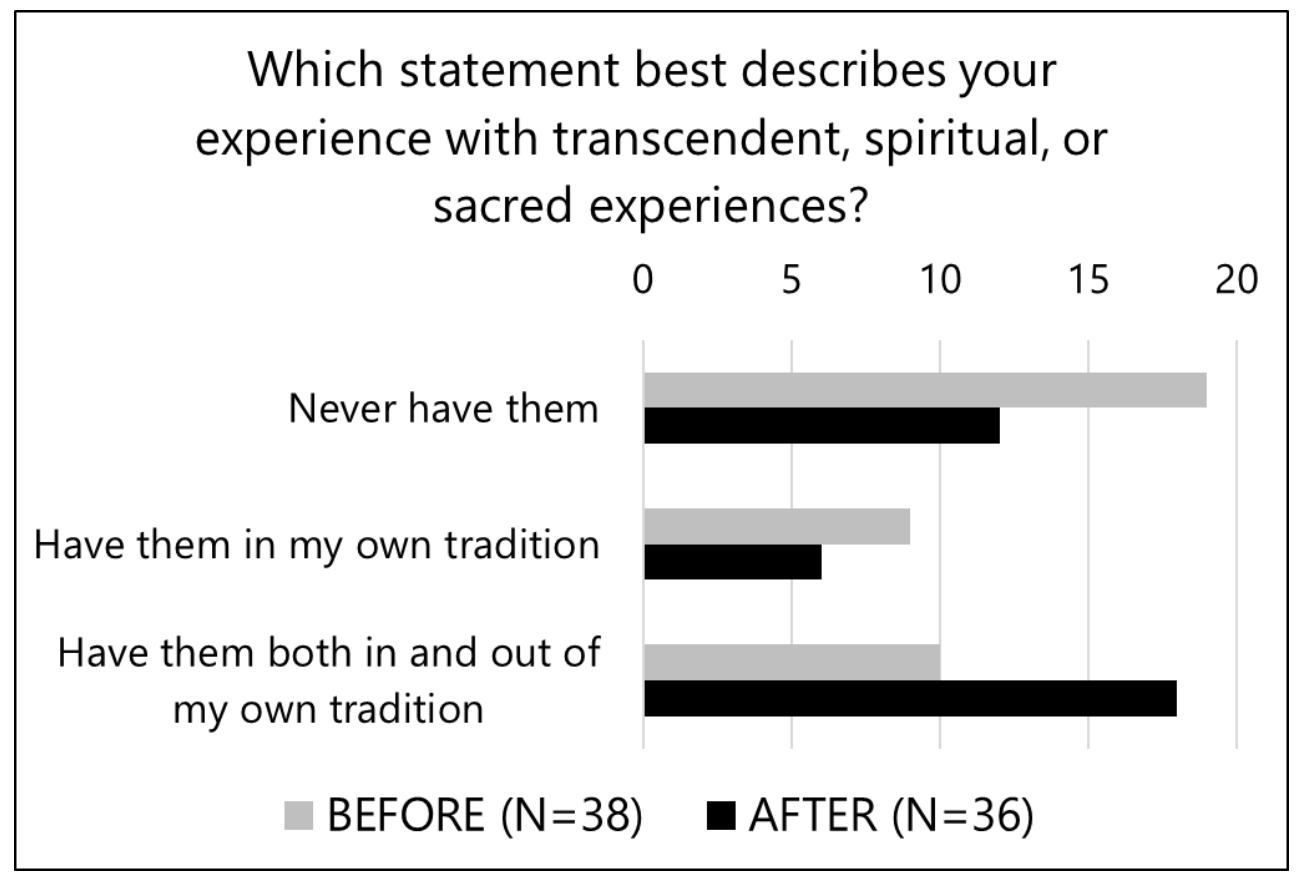

Figure 4. Experience with transcendent, spiritual, or sacred experiences, comparing pre- vs. post-.

\section{Belief Orthodoxy}

Another way that we assessed the impact of these study abroad/away experiences was on students' reported levels of belief in the teachings of their "religion or religious community." This question deliberately excluded those who had earlier reported having no identification with a specific religious tradition, leaving us with 29 students who answered the question. The prompt gave 
students five options to express their degree of belief in their religion's teachings: "wholehearted," "many or most of the teachings," "some teachings are hard for me to believe," "many or most" teachings are "hard for me to believe," or "I do not believe" in the teachings of my religion. In their pre-experience recollections, ten students reported believing wholeheartedly or "many/most" of their religion's teachings, 17 reported that some teachings are hard for them to believe, while five said that most teachings were hard to believe or that they simply did not believe their religious community's teachings.

When we compare answers pre- vs. post-January class in Figure 5, we find that 12 of 29 (about two in five) reported moving in one direction or another in terms of their levels of belief orthodoxy, but not in consistent directions: five students reported moving in a more doubting direction while seven reported moving in a more believing direction. Changes occurred in students enrolled in every course, except "Roots of Mindfulness" (which had the least explicit religious focus).

One factor that tended to be associated with movement in belief orthodoxy was a student's level of belief before the experience. Of the nine who reported that they believed many or most of their religion's teachings before the course, four moved to "believe wholeheartedly," four stayed the same, and one moved to "some teachings are hard for me to believe." Of the four who said in their pre-experience recollection that many/most of their religion's teachings are hard for them to believe, two reported staying the same while the other two now claimed that they "do not believe" in their religion's teachings. This may suggest a polarizing effect of sorts, affirming and strengthening a student's pre-existing belief or disbelief.

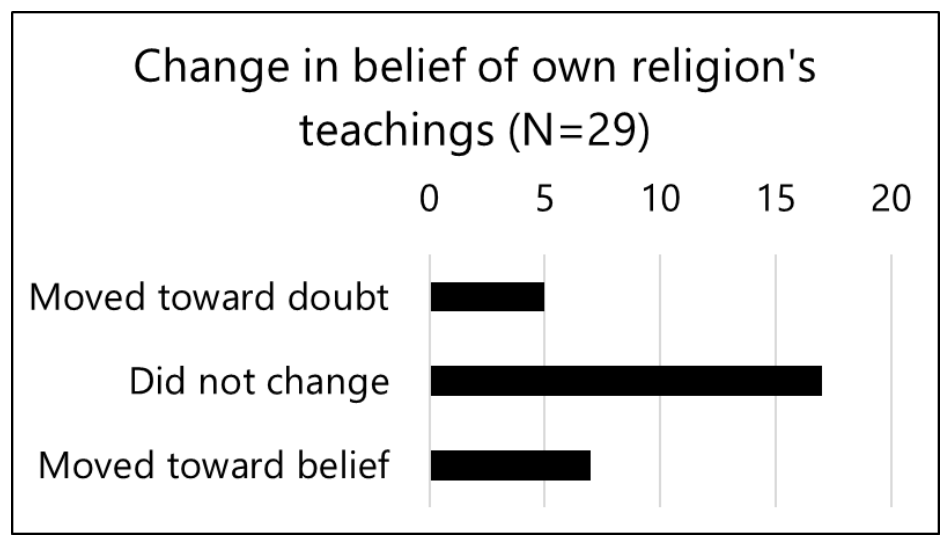

Figure 5. Changes in belief orthodoxy, comparing pre- vs. post-.

\section{Religious Particularism vs. Universalism}

Our final question asked students whether, in general, they were more likely to agree that "my religion is the only true faith leading to eternal life" or that "many religions can lead to eternal life." In contrast to the other questions, we did not find much substantive change in student responses when comparing their pre- vs. post-study abroad/away recollections. Of the 30 students who answered the question in the pre-January recollection, 23 indicated more agreement with the universalistic option while seven indicated more agreement with the particularistic option. Of those, 
the only change was among the seven students with particularistic views, two of who moved to a more universalistic viewpoint after their study abroad/away experience. Of those two students, one identified as Evangelical and one as non-denominational Christian; one took the "Pilgrimage" course (which contained a heavy exposure to Catholicism) while the other took the "Islam in America" course. Nonetheless, more than nine in ten students reported no change in their views about their religion's exclusive claims to grant access to eternal life.

\section{Conclusion and Implications}

It is important to understand how students' religious identities might affect and be affected by their off-campus courses. Cultivating this awareness in students and those who support them can lead to better educational experiences: augmentation of pre-departure preparation, improvement of on-site instruction and activities, and creation of more potent reflection and efficacious re-entry into home campus life. Knowing how deeply a factor students' faith is to them will manifest abroad externally in how students relate to new people and communities, as well as internally in how they understand themselves and the course in these new contexts.

Here we have detailed the results of an exploratory study of how study abroad experiences and religious identity inform and reinforce one another among a convenience sample of students at our institution. We emphasize the contingent and tentative nature of our conclusions based on the nature of our sample and hope that it motivates subsequent research to better understand this important phenomenon. While our data are admittedly limited, we believe that they are not without value and suggest some tentative conclusions and patterns.

A number of students in this survey, for example, indicated that a spiritual or transcendent experience occurred for them during their trip, either inside or outside of their own faith tradition. Being aware of the probabilities of such occurrences for students should help administrators and instructors develop early the proper language and activities for students to process these new experiences as they relate to course objectives and overall holistic development. Study abroad/away is recognized as a high-impact practice in higher education, but its transformative impact on students' religious identity is rarely discussed. Experiences within and without students' own religious traditions can be both a source of validation and empowerment, and one of immense stress. While it is not necessary nor advisable for program administrators and directors to assume the role of chaplain or therapist, preparing for discussions of a religious and spiritual nature can only elevate the educational support offered to students off-campus, especially if these experiences have an intentional component that focuses on religious and/or spirituality:

A state of disequilibrium can promote change, but most effectively only with the proper support. Students need mentors who can provide support, wisdom, challenge, and counsel. (Miller-Perrin \& Thompson, 2014, p. 86)

This study indicates no drastic shifts in students' faith or conversions off-campus. It is a common misconception that courses with strong religious components in U.S. higher education are designed to challenge students' faith and to push them toward more progressive, pluralistic notions of religious truth and certainty. However, that is not an inevitable result for students. In our examination of this question, at least, we did not observe much evidence of this among our students. For example, less than ten percent of students in this study indicated a change in their 
ideas about their religion's monopoly on truth. Furthermore, if already convinced of the veracity of their faith beforehand, students generally became even firmer in their beliefs. There is little evidence of any fundamental questioning of one's religious background, though some movement towards greater openness and inclusivity within their traditions is observable among our student sample.

Most students in this study started with a positive attitude towards other religions and their adherents. When considering their views after the off-campus portion of the course, student attitudes toward minority religious groups rose somewhat in favorability. This is notable since it reflects the main objectives of course instructors that students become more knowledgeable of and accepting of so-called "out-groups." Planning to host dialogues about religious identity will further enable instructors to achieve their academic goals as well as ensure that many of their "out-group" students feel recognized and appreciated while studying off-campus.

With this kind of dialogue open, staff and instructors will be better prepared to deal with unforeseen or unintended consequences. For example, in this study, students in the "The Roots of Mindfulness" course expressed a somewhat diminished favorability towards atheists and agnostics compared to pre-trip levels. The course was by no means designed to affect perception towards any group negatively, and yet, this result still occurred. Being aware of the possibility that course objectives and outcomes may differ widely for some learners will encourage instructors to consider opening new channels for discussion.

Ultimately, prioritizing awareness of the influence of and potential shifts in student religious identity indicates educators' care for students as they pass through challenging experiences abroad. From an integrated perspective, a student's religious identity is deeply interconnected with their learning and their interaction with others. We validate students more completely and design educational experiences more comprehensively when taking this aspect of their identity into account.

How then to break the silence-i.e., puncture the religion taboo-with conversations that will generate greater awareness and support student growth? There is a continuing need for conversational primers or guidelines for faculty and staff providing pre-departure training, course instruction, and re-entry activities.

Building upon the insights of Tim Elliot and Lorien Romito (2018) and Elijah Stiegler (2015), we conclude by offering the following as springboards for student discussion:

1. How comfortable are you speaking about religion and participating in religious rites, both within and outside your faith?

2. What are your personal experiences and attitude toward religion(s)? What experiences have you had with the religions represented by your peers, the course, and the study site?

3. How has religion influenced your identity, or the identity of those in your family, community, and classroom? How is religion influencing the lives of those in the location you are studying? 
4. Explain how you feel adopting the following attitudes will help as you encounter those of other faiths in your study location:

- Being tolerant.

- Withholding judgment.

- Being curious.

- Being respectful.

5. In what circumstances have you found yourself judging others based on their religious beliefs or behavior? In what ways do you see religion influencing the behaviors of your classmates and local people(s) towards each other in your study location?

6. How and in what circumstances have you employed strategies to avoid, speak around, or indirectly address questions about religion? Have you experienced or noticed similar strategies being used in the study location by your classmates and local peoples?

7. Do you plan on attending religious services in the study location? What do you hope to gain? Will you seek out friendships in these religious communities?

8. How do you see yourself on this course: student, seeker, pilgrim, tourist, etc.?

9. Do you hope or expect to have spiritual experiences? If so, what might you anticipate these will be like, and under what conditions do you think they will occur?

10. How do you think your knowledge and attitude toward religion(s) might change during the course?

11. How do you think learning about and interacting with those of other faiths in the class and in the study abroad location will affect your attitude towards them?

12. How will understanding the religion(s) of this location help you gain greater insight into the local culture, community, nation, and humanity generally?

13. Who might you turn to at home and at the study site to discuss topics of a personal religious nature?

As a parting thought and recommendation, when the taboo is punctured and dialogue is flowing, remember that silence can again become a productive tool for new knowledge and growth: It's ok for things to "stop making sense" for a time without feeling the need to resolve them for students all at once (Mitchell, 2015, p. 61).

\section{Bibliography}

Braskamp, L., Braskamp, D., \& Merrill, K. (2009). Assessing progress in global learning and development of students with education abroad experiences. Frontiers: The Interdisciplinary Journal of Study Abroad, 18, 101-118.

Dinani, T. (2018). Faith development while abroad amongst African American students. Frontiers: The Interdisciplinary Journal of Study Abroad, 30(1), 8-19. 
Elliott, T. L., Hyndman III, W. T., Larkin, N., Scarboro, D., \& Woolf, M. (2018). For God's sake: Religion and study abroad: Introduction. Frontiers: The Interdisciplinary Journal of Study Abroad, 30(1), i-vi.

Elliott, T. L., \& Romito, L. (2018). Talking religion: Religious diversity in study abroad advising. Frontiers: The Interdisciplinary Journal of Study Abroad, 30(1), 1-7.

Gardner, H. (2006). Changing minds: The art and science of changing our own and other people's minds. Boston, MA: Harvard Business School Press.

Geisinger, K. F. (2010). Bogardus social distance scale. In I. Weiner \& W. E. Craighead (Eds.), The Corsini encyclopedia of psychology. Hoboken, NJ: John Wiley \& Sons, Inc.

Gray, K. M., \& Savicki, V. (2015). Study abroad reentry: Behavior, affect, and cultural distance. Frontiers: The Interdisciplinary Journal of Study Abroad, 26, 264-278.

Li, M., Olson, J. E., \& Frieze, I. H. (2013). Students' study abroad plans: The influence of motivational and personality factors. Frontiers: The Interdisciplinary Journal of Study Abroad, 23, 73-89.

Miller-Perrin, C., \& Thompson, D. (2010). The development of vocational calling, identity, and faith in college students: A preliminary study of the impact of study abroad. Frontiers: The Interdisciplinary Journal of Study Abroad, 29, 87-103.

Miller-Perrin, C., \& Thompson, D. (2014). Outcomes of global education: External and internal change associated with study abroad. New Directions for Student Services, 146, 77-89.

Mitchell, K. (2015). The immersion experience: Lessons from study abroad in religion. Teaching Theology \& Religion, 18(1), 56-62.

Nelson, S. C. (2008). Feeling thermometer. In P. J. Lavrakos (Ed.), The encyclopedia of survey research methods (p. 276). Thousand Oaks, CA: Sage Publishing.

Palmer, N. W. (2015). Inverting the object of study: Recalibrating the frame of reference in study abroad experiences. Teaching Theology \& Religion, 18(1), 63-72.

Poag, T., \& Sperandio, J. (2015). Changing minds: The impact of study abroad components on students' changes in their religious faith. Frontiers: The Interdisciplinary Journal of Study Abroad, 26, 144166.

Putnam, R. D., \& Campbell, D. E. (2010). American grace: How religion divides and unites us. New York, NY: Simon and Schuster.

Rockenbach, A. N., Hudson, T. D., Mayhew, M. J., Correia-Harker, B. P., \& Morin, S. M. (November 2019). Friendships matter: The role of peer relationship in interfaith learning and development. Retrieved from https://www.ifyc.org/sites/default/files/resources/IDEALS-2019-FriendshipsMatter.pdf

Rosenblith, S., \& Bailey, B. (2007). Comprehensive religious studies in public education: Educating for a religiously literate society. Educational Studies: Journal of the American Educational Studies Association, 42(2), 93-111.

Saldaña, J. (2015). The coding manual for qualitative researchers (3rd ed.). Thousand Oaks, CA: Sage Publications.

Siegler, E. (2015). Working through the problems of study abroad using the methodologies of religious studies. Teaching Theology \& Religion, 18(1), 37-45.

Smidt, C. E., Kellstedt, L. A., \& Guth, J. L. (2009). The Oxford handbook of religion and American politics. Oxford, New York: Oxford University Press.

Sullivan, J. L., Piereson, J., \& Marcus, G. E. (1979). An alternative conceptualization of political tolerance: Illusory increases 1950s-1970s. American Political Science Review, 73(3), 781-794.

Unkule, K. (2018). Seeing all beings as oneself: Internationalizing higher education for universal harmony. Frontiers: The Interdisciplinary Journal of Study Abroad, 30(1), 33-41.

Willis, O. (2012). The study abroad experience: Where does religion fit? Journal of Global Citizenship \& Equity Education, 2(1), 1-18.

Wright, J., \& Nichols, R. (2014) The social cost of atheism: How perceived religiosity influences moral appraisal. Journal of Cognition and Culture, 14, 93-115. 


\section{APPENDIX: FULL SURVEY QUESTIONAIRE}

What year are you currently?

first-year

sophomore

junior

senior?

In the 2019 CentreTerm, which of the following courses did you take?

REL 310 / ARH 310: The Art of Pilgrimage

PSY 451 / ENS 257: The Roots of Mindfulness

REL 334: Islam in America

FYS 160: Imagining Home: Global Migrations and Religious Identities

What is your gender?

Male

Female

Other (SPECIFY)

Which option most closely matches your racial and/or ethnic identification?

White

Black

Hispanic/Latino

Asian

Native American

Other or mixed race (SPECIFY)

Which county did you spend most of your time growing up in? (e.g. Boyle County, Kentucky, Davidson County, Tennessee, etc.) (OPEN ENDED)

What is your present religion, if any? List the specific denomination, community, tradition, etc., include atheist/agnostic if applicable. (OPEN ENDED)

Thinking about when you were a child, in what religion were you raised, if any? List the specific denomination, community, tradition, etc., include atheist/agnostic if applicable. (OPEN ENDED)

Aside from weddings and funerals, how often do you attend religious services...

more than once a week

once a week

once or twice a month

a few times a year

seldom

never

Generally speaking, how important is religion in your life?

very important 
somewhat important

not too important

not at all important

Now we have some questions about your personal religious/spiritual beliefs as well as your knowledge of and feelings about various religious groups in American society.

For each of these questions, please think back to December 2018 BEFORE you took this January's CentreTerm course. Answer each of the questions based on how you WOULD HAVE answered each question BEFORE you took the class.

Thinking back to December 2018, before the CentreTerm course, which statement came closest to expressing what you believed about God?

I knew God really exists and I had no doubts about it.

While I had doubts, I feel that I did believe in God.

I found myself believing in God sometimes, but not at other times.

I didn't believe in a personal God, but I did believe in a Higher Power of some kind.

I didn't know whether there is a God and I didn't believe there is any way to find out.

I didn't believe in God.

Before taking the January CentreTerm course, which statement came closest to expressing what you believed about transcendent, spiritual, sacred, or mystical experiences?

I never or rarely had transcendent, spiritual, sacred, or mystical experiences.

I had transcendent, spiritual, sacred, or mystical experiences primarily within my own religious tradition or contexts.

I had transcendent, spiritual, sacred, or mystical experiences both in my own as well as other traditions or contexts.

I had transcendent, spiritual, sacred, or mystical experiences primarily outside my own religious tradition or contexts.

Thinking about your religion (if any), which of the following statements came CLOSEST to your view BEFORE you took the CentreTerm course? My church or religious community should:

Return to traditional beliefs and practices

Maintain current beliefs and practices

Adjust traditional beliefs and practices in light of new circumstances

Adopt modern beliefs and practices

Not applicable: I do not identify with a religion or religious community.

Which statement came CLOSEST to your own views BEFORE taking the CentreTerm course even if none is exactly right?

I believe wholeheartedly in all of the teachings of my religion or religious community.

I believe many or most of the teachings of my religion or religious community.

Some of the teachings of my religion or religious community are hard for me to believe.

Many of most of the teachings of my religion or religious community are hard for me to believe.

I do not believe in the teachings of my religion or religious community.

Not applicable: I do not identify with a religion or religious community. 
Which of these two statements came closer to your own views BEFORE taking the CentreTerm course, even if neither is exactly right?

My religion is the only true faith leading to eternal life.

Many religions can lead to eternal life.

Not applicable: I do not identify with a religion or religious community.

Before taking the CentreTerm course, please rate the level of agreement that you had with the following statement: "I see our nation's increasing religious diversity as an overall positive trend for the future."

Strongly Agree

Somewhat Agree

Somewhat Disagree

Strongly Disagree

For the following religious groups, please indicate on a scale of 0-100 your favorability toward each group BEFORE taking the CentreTerm

Ratings between 50 and 100 mean that you felt favorable and warm toward the group. Ratings between 0 and 50 mean that you didn't feel favorably toward the group and that you didn't care too much for that group. You would rate the group at the 50 degree mark if you didn't feel particularly warm or cold toward the group.

$0-100 \%$ scale

[RANDOMIZE]

Roman Catholics

Evangelical "born again" Protestants (e.g. Baptists, Pentecostals, etc.)

Mainline Protestants (e.g. Methodists, Presbyterians, Episcopalians, etc.)

Latter-day Saints (Mormons)

Eastern Orthodox Christians

Jehovah's Witnesses

Jews

Muslims

Buddhists

Hindus

Atheists/Agnostics

Shintos

Baha'is

Native American religionists

Sikhs

For each of the following religious groups, please indicate the option that best represents your highest level of social acceptance BEFORE taking the January CentreTerm course.

For example, if you would be willing to accept a group as a close personal friend but NOT as a 
marriage partner, select "I would be willing to accept as a close personal friend."

Or if you would be willing to accept as a fellow citizen, but perhaps not as a neighbor on the same street, coworker, close personal friend, or marriage partner, select "I would be willing to accept as a citizen of my country."

I would be willing to accept as a close relative by marriage.

I would be willing to accept as a close personal friend.

I would be willing to accept as a neighbor on the same street.

I would be willing to accept as a coworker.

I would be willing to accept as a citizen in my country.

I would be willing to accept as a visitor to my country.

I would exclude from my country.

[RANDOMIZE]

Roman Catholics

Evangelical "born again" Protestants (e.g. Baptists, Pentecostals, etc.)

Mainline Protestants (e.g. Methodists, Presbyterians, Episcopalians, etc.)

Latter-day Saints (Mormons)

Eastern Orthodox Christians

Jehovah's Witnesses

Jews

Muslims

Buddhists

Hindus

Atheists/Agnostics

Shintos

Baha'is

Native American religionists

Sikhs

Please indicate how you WOULD HAVE answered this question BEFORE taking the January CentreTerm course about [LEAST LIKED GROUP】

I support a member of this group being permitted to make a public speech in my city.

I support a member of this group being permitted to run for political office in my city.

I support this group having a place of worship in my city.

I support a close friend or family member converting to this group's religion and participating in the religious community.

Assuming that the candidate is qualified, I would enthusiastically vote for a member of this group if my party nominated him or her for the presidency.

Strongly agree

Somewhat agree

Somewhat disagree

Strongly disagree 
BEFORE taking the CentreTerm course, about what percentage of the United States population WOULD YOU HAVE SAID belong to each of the following groups (to the best of your knowledge)?

$0-100 \%$ scale

[RANDOMIZE]

Roman Catholics

Evangelical "born again" Protestants (e.g. Baptists, Pentecostals, etc.)

Mainline Protestants (e.g. Methodists, Presbyterians, Episcopalians, etc.)

Latter-day Saints (Mormons)

Eastern Orthodox Christians

Jehovah's Witnesses

Jews

Muslims

Buddhists

Hindus

Atheists/Agnostics

Shintos

Baha'is

Native American religionists

Sikhs

Now we have a few more questions on similar topics as before. This time, answer each of the questions based on how you CURRENTLY THINK AND FEEL, RIGHT NOW, after taking January's CentreTerm course.

Which statement comes closest to expressing what you believe about God, right now?

I knew God really exists and I had no doubts about it.

While I had doubts, I feel that I did believe in God.

I found myself believing in God sometimes, but not at other times.

I didn't believe in a personal God, but I did believe in a Higher Power of some kind.

I didn't know whether there is a God and I didn't believe there is any way to find out.

I didn't believe in God.

Which statement comes closest to expressing what you believe about transcendent, spiritual, sacred, or mystical experiences, as of today and right now?

I never or rarely had transcendent, spiritual, sacred, or mystical experiences.

I had transcendent, spiritual, sacred, or mystical experiences primarily within my own religious tradition or contexts.

I had transcendent, spiritual, sacred, or mystical experiences both in my own as well as other traditions or contexts. 
I had transcendent, spiritual, sacred, or mystical experiences primarily outside my own religious tradition

Thinking about your religion (if any), which of the following statements comes CLOSEST to your current view? My church and religious community should:

Return to traditional beliefs and practices

Maintain current beliefs and practices

Adjust traditional beliefs and practices in light of new circumstances

Adopt modern beliefs and practices

Not applicable: I do not identify with a religion or religious community.

Which statement comes closest to your own views as of today - even if none is exactly right?

I believe wholeheartedly in all of the teachings of my religion or religious community.

I believe many or most of the teachings of my religion or religious community.

Some of the teachings of my religion or religious community are hard for me to believe.

Many of most of the teachings of my religion or religious community are hard for me to believe.

I do not believe in the teachings of my religion or religious community.

Not applicable: I do not identify with a religion or religious community.

Which of these two statements comes closer to your own views today and right now- even if neither is exactly right?

My religion is the only true faith leading to eternal life.

Many religions can lead to eternal life.

Not applicable: I do not identify with a religion or religious community.

As of today, I see our nation's increasing religious diversity as an overall positive trend for the future.

Strongly Agree

Somewhat Agree

Somewhat Disagree

Strongly Disagree

For the following religious groups, please indicate on a scale of 0-100 your favorability toward each group as of today, after taking the CentreTerm course.

Ratings between 50 and 100 mean that you felt favorable and warm toward the group. Ratings between 0 and 50 mean that you didn't feel favorably toward the group and that you didn't care too much for that group. You would rate the group at the 50 degree mark if you didn't feel particularly warm or cold toward the group.

\section{[RANDOMIZE]}

Roman Catholics

Evangelical "born again" Protestants (e.g. Baptists, Pentecostals, etc.)

Mainline Protestants (e.g. Methodists, Presbyterians, Episcopalians, etc.)

Latter-day Saints (Mormons)

Eastern Orthodox Christians

Jehovah's Witnesses 
Jews

Muslims

Buddhists

Hindus

Atheists/Agnostics

Shintos

Baha'is

Native American religionists

Sikhs

For each of the following religious groups, please indicate the option that best represents your highest level of social acceptance today and right now, AFTER taking the January CentreTerm course.

For example, if you would be willing to accept a group as a close personal friend today but NOT as a marriage partner today, select "I would be willing to accept as a close personal friend."

Or if you would be willing to accept as a fellow citizen, but perhaps not as a neighbor on the same street, coworker, close personal friend, or marriage partner, select "I would be willing to accept as a citizen of my country."

I would be willing to accept as a close relative by marriage.

I would be willing to accept as a close personal friend.

I would be willing to accept as a neighbor on the same street.

I would be willing to accept as a coworker.

I would be willing to accept as a citizen in my country.

I would be willing to accept as a visitor to my country.

I would exclude from my country.

[RANDOMIZE]

Roman Catholics

Evangelical "born again" Protestants (e.g. Baptists, Pentecostals, etc.)

Mainline Protestants (e.g. Methodists, Presbyterians, Episcopalians, etc.)

Latter-day Saints (Mormons)

Eastern Orthodox Christians

Jehovah's Witnesses

Jews

Muslims

Buddhists

Hindus

Atheists/Agnostics

Shintos

Baha'is

Native American religionists

Sikhs 
Please indicate your answer for each statement based on your opinion today and right now, AFTER taking the January CentreTerm course about [LEAST-LIKED GROUP]:

I support a member of this group being permitted to make a public speech in my city.

I support a member of this group being permitted to run for political office in my city.

I support this group having a place of worship in my city.

I support a close friend or family member converting to this group's religion and participating in the religious community.

Assuming that the candidate is qualified, I would enthusiastically vote for a member of this group if my party nominated him or her for the presidency.

Strongly Agree

Somewhat Agree

Somewhat Disagree

Strongly Disagree

To the best of your present knowledge today, about what percentage of the United States population is each of the following groups as of today?

\section{$0-100 \%$ scale}

\section{[RANDOMIZE]}

Roman Catholics

Evangelical "born again" Protestants (e.g. Baptists, Pentecostals, etc.)

Mainline Protestants (e.g. Methodists, Presbyterians, Episcopalians, etc.)

Latter-day Saints (Mormons)

Eastern Orthodox Christians

Jehovah's Witnesses

Jews

Muslims

Buddhists

Hindus

Atheists/Agnostics

Shintos

Baha'is

Native American religionists

Sikhs

Thank you so much for the time you have taken to complete this survey. These are the last two questions. We are almost done.

In a few sentences or paragraphs, please describe how your religious background, identity, and/or belief (or lack thereof) influenced your CentreTerm 2019 experience? (OPEN ENDED)

In a few sentences or paragraphs, please describe how your CentreTerm 2019 experience influenced your religious identity and/or belief (or lack thereof)? (OPEN ENDED) 
Optional: if you would like to be entered into a drawing for gift cards from the Centre Study Abroad Office, please provide your email address below.

Your email address will not be matched to your responses, so this will not affect the anonymity of the survey responses that you have entered. 